\title{
THE MICROHARDNESS OF ENAMEL AND DENTIN
}

\author{
R. G. CRAIG, PH.D., AND F. A. PEYTON, D.Sc.
}

University of Michigan, School of Dentistry, Ann Arbor, Mich.

$\mathrm{T}$ HE hardness of enamel and dentin has been determined by a variety of methods including abrasion, ${ }^{1,2}$ pendulum, ${ }^{3}$ seratch, ${ }^{4-7}$ and indentation ${ }^{8-13}$ technics. Since the hardness of enamel and dentin has been shown to have considerable local variations, the methods using a microscratch or microindentation have been preferred. One of the more common types is the Knoop diamond indenter ${ }^{14}$ which has been used by a number of investigators. ${ }^{10,12,15,16}$ It should be mentioned, however, that in spite of the fact that the indentations are extremely small, they still represent a macroindentation when compared to the microstructure of enamel and dentin.

The majority of the published hardness data for enamel and dentin has been measured on ground sections, although several papers ${ }^{10,13}$ reported the hardness of intact enamel surfaces. The conclusions in regard to the difference in hardness from one section of a tooth to another are at times in variance with each other. This study of dentin and enamel was undertaken in an attempt to establish any trends in hardness existing from one area of a tooth to another or between different types of teeth. With this purpose in mind, this research did not attempt to relate the hardness values to the histologic tooth structure, but a sufficiently large number of hardness measurements were made so that the data could be treated on a statistical basis.

\section{EXPERIMENTAL}

Specimen Preparation.-Mature, freshly extracted, noncarious teeth were imbedded in Ward's Bio-Plastic by suspending them in a Vaughn ring containing the polymer mixed with the catalyst and accelerator. The incorporated air was removed by degassing in a vacuum chamber, after which the polymerization was hastened by placing the ring in an oven at $50^{\circ} \mathrm{C}$. for 4 hours or more.

The imbedded teeth were sectioned by using a water-spray cooled carborundum wheel, $0.33 \mathrm{~mm}$. thick. The specimens were eut so that the sections were 1 to $2 \mathrm{~mm}$. thick, the first cut being made at or slightly below the occlusal surface or incisal edge. Specimens cut in a direction mesial to distal or buccal to lingual were cut so that the first section was the lingual or mesial surface, respectively. The thickness of each section was measured with a micrometer and the surfaces to be tested were polished by the successive use of $240 \mathrm{~A}, 400 \mathrm{~A}$, and 600A Norton Tufback Speed wet paper supported by a glass slab, followed by

\footnotetext{
This report represents the partial results of studies supported by Contract No. D-462 between the U. S. Public Health Service, National Institute of Health, and the University of Michigan.

Received for publication Dec. 9, 1957.
} 


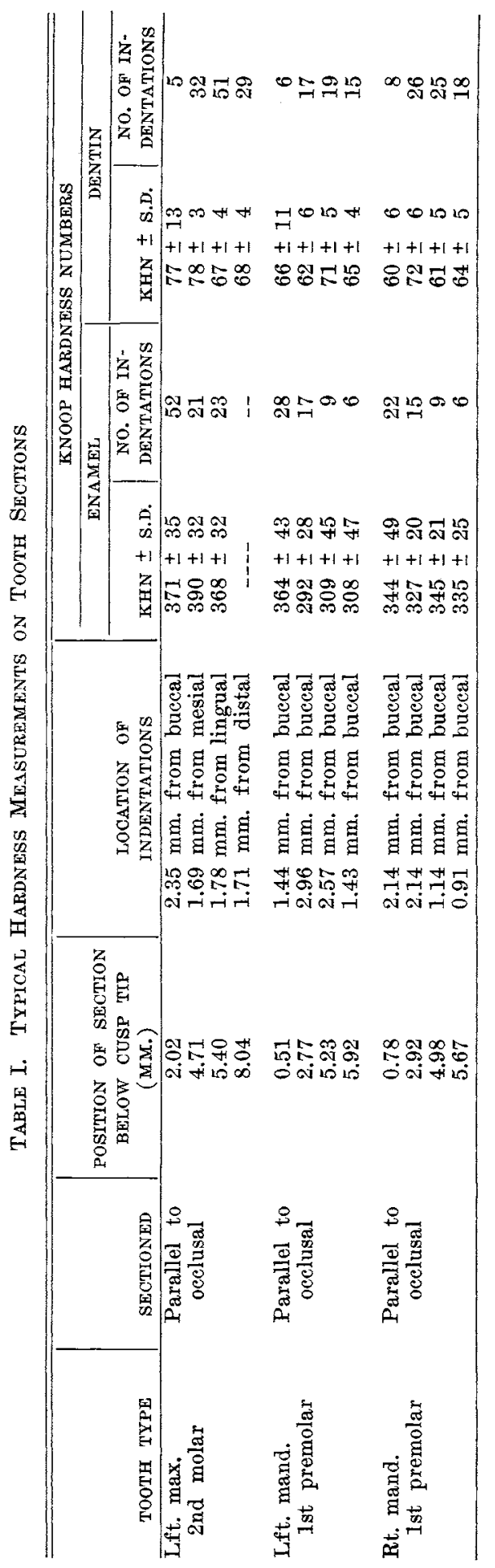


separate polishings with Shamva and CRO metallographic polishes at low speeds on a wet polishing wheel. This polishing procedure removed approximately $0.18 \mathrm{~mm}$. of a tooth section.

The distance of the surface to be tested from the reference surface could be estimated knowing the thickness of the sections, and the amounts removed by the carborundum wheel and the polishing procedure.

The polished specimens were mounted on glass microscope slides by attaching the edges of the specimens to the glass with red utility wax, and using a hand press to ensure that the surface to be tested was parallel to the table of the hardness tester.

Hardness Testing.-An "MO" Tukon microhardness tester was used with a Knoop diamond indenter to determine the hardness values. The polished sections mounted on microscope slides were fastened to the mechanical specimen stage of the hardness tester. Loads from 25 to $200 \mathrm{Gm}$. on the indenter were investigated and it was found that a 50-gram load applied to the specimen for 15 seconds represented optimum conditions. This procedure resulted in well-defined indentations with a minimum of fractures around the edges. The average length of the long diagonals for enamel and dentin was 0.046 and 0.101 $\mathrm{mm}$, respectively. The ratio of the long to short diagonal of the indentations, which should be approximately 7.1, was not taken as a criterion for a satisfactory indentation since contraction of the short diagonal occurred due to retarded elastic recovery. This phenomenon was particularly pronounced in dentin. The main criteria for accepting an indentation value were clearness of outline and absence of flaws in the tooth in the area of the measurement.

The indentations were made in a line from mesial to distal or from buccal or labial to lingual for sections cut parallel to the ocelusal surface or incisal edge. For sections cut mesial to distal or buccal to lingual the measurements were made in the direction of the distal or lingual surface. In one case (tooth No. 25) the indentations were taken in a transverse section around the tooth at a definite distance from the enamel edge or the dentinoenamel junction.

\section{RESULTS}

Typical experimental results obtained on transverse sections of teeth are tabulated in Table I. Three types of teeth are listed along with the type and position of the sections, the location of the indentations, the number of indentations, the average Knoop hardness numbers for each section, and the respective standard deviations.

The Knoop values for enamel varied considerably from one location to another in the same section as indicated in Table I by the standard deviation values ranging from \pm 20 to \pm 49 . Pronounced differences existed between the hardness values of different sections of the same tooth. The average hardness values of enamel for the 3 teeth listed were 376,326 , and 338 , respectively. Thus, smaller deviations were observed between these averages for different teeth than between average values for different sections of a single tooth. 
In general, no definite trend in the hardness of enamel was observed from the occlusal surface to the cervical margin or from the dentinoenamel junction to the outer enamel surface. Some slight indications were found that the enamel was harder at the cusp and outer surface than at the cervical margin or the dentinoenamel junction, but the order of the differences was approximately 25 Knoop numbers, which is less than the average standard deviation, and thus no definite statement can be made.

It should be pointed out that due to the large number of hardness determinations, single values having a deviation greater than 2 times the standard deviation from the average hardness value were discarded on the basis that they were outside the range of experimental errors and probably represented inordinately high or low areas of hardness. These values possessing large deviations from the average will be discussed later in this section.

The Knoop hardness numbers of the dentin for a single transverse section also varied and standard deviations from \pm 3 to \pm 13 were found. Different average hardness values were obtained for the sections of the same tooth and no general trend in the hardness of dentin in teeth was observed. The average standard deviation for dentin is only \pm 5 ; however, this represents approximately 7.5 per cent error compared with about 10.8 per cent error for the enamel values.

Although no general trends were observed in the hardness values of dentin and enamel from one portion of a tooth to another, in general more variation in hardness values was obtained in the first section below the ocelusal surface or the incisal edge than in the remaining sections.

The hardness values obtained on 5 sections of tooth No. 10 are presented in Fig. 1. The tooth, a left mandibular first premolar, was sectioned parallel to the occlusal surface and the Knoop hardness values were measured on surfaces 1 to 5 in a line from the mesial to the distal edge. Thus, the plot represents the hardness at various distances from the mesial edge. The points have been connected only to show continuity of surface and not to represent the change of hardness between points. The dispersion of the enamel values is very noticeable, while the variation in dentin values is less pronounced. The decrease in the thickness of enamel and the increase in thickness of dentin from surface 1 to 5 is also evident. The hardness values of the dentin and enamel in the region of the dentinoenamel junction were the lowest values obtained. Several reasons are possible for this fact: (1) the indentations in the adjacent enamel region had a greater probability of being partly in a longitudinal soft layer than those farther from the dentinoenamel junction; (2) the indentations in the adjacent dentin may be affected by a high concentration of dentinal fibers and/or interglobular areas; and (3) the polishing of a transverse section of enamel and dentin, having different hardness values, results in somewhat curved surfaces near the dentinoenamel junction which would yield too large an indentation and thus too low a Knoop hardness number.

Various types of teeth were sectioned either transversely or longitudinally and the hardness values of dentin and enamel obtained are reported in Table 
II. The Knoop hardness numbers listed are weighted averages of individual values obtained on all sections of a single tooth. The standard deviation and the number of indentations for each tooth are also tabulated. If the number of indentations for each tooth is disregarded, the over-all average hardness value of enamel and dentin is 343 and 68 , respectively. The standard deviations for these over-all averages are \pm 23 and \pm 3 which are low when compared with the standard deviation for a single tooth and, therefore, no trend could be detected between the hardness values of the various types of teeth.

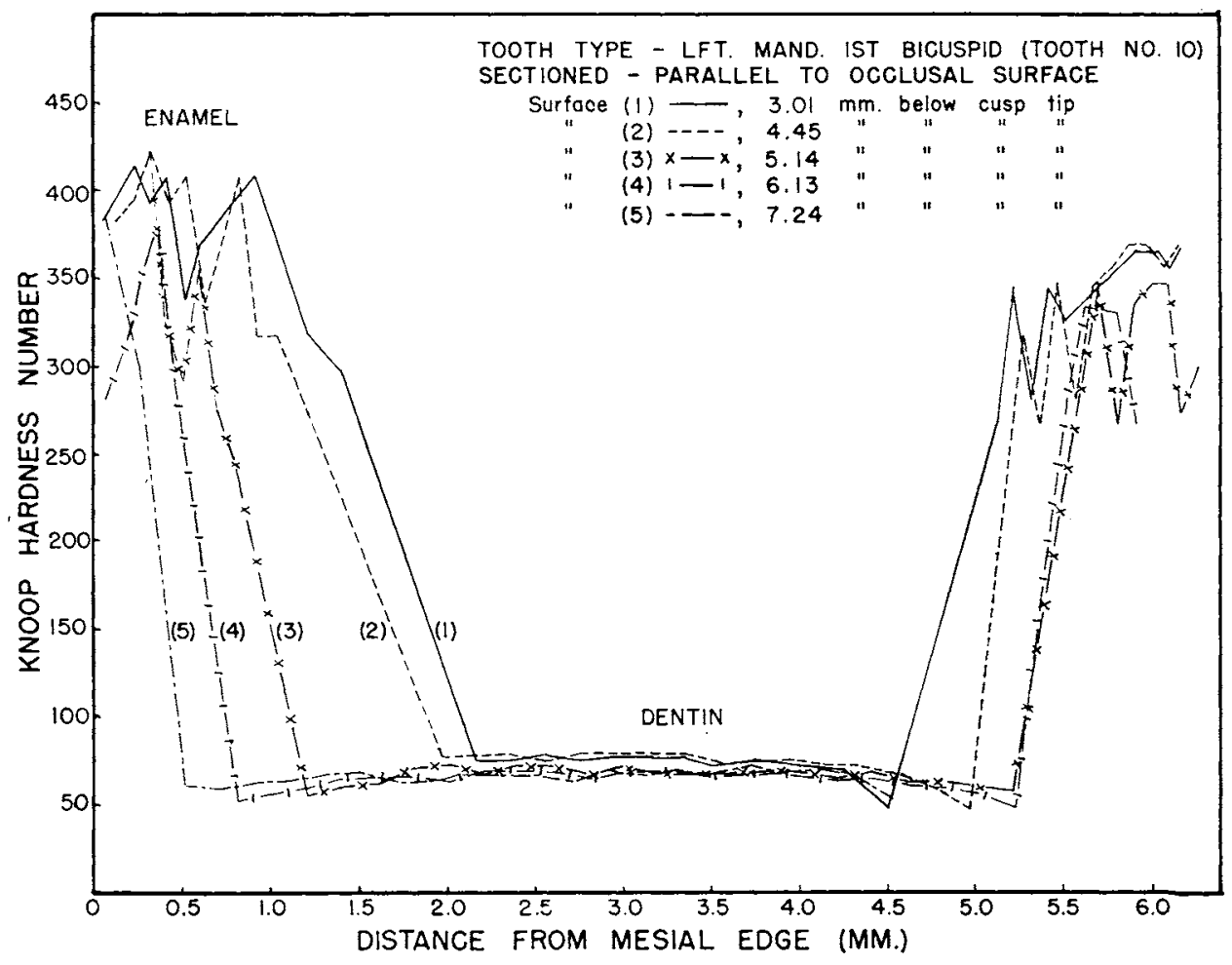

Fig. 1.-Enamel and dentin hardness values of tooth sections.

The enamel hardness value of $418 \pm 60$ for tooth No. 25 and the dentin hardness values of $76 \pm 8$ for tooth No. 26 and $60 \pm 7$ for tooth No. 14 represent values having the largest deviations from the over-all averages. These values were a result of high or low hardness values in a single section of the tooth which only emphasizes that as large or larger variations can be present in a single tooth as between two teeth.

As previously mentioned, hardness values having deviations greater than twice the standard deviation were disearded as being outside the region of experimental error. The number of these disearded values, both high and low, amounted to approximately 15 per cent of the total number of indentations. 


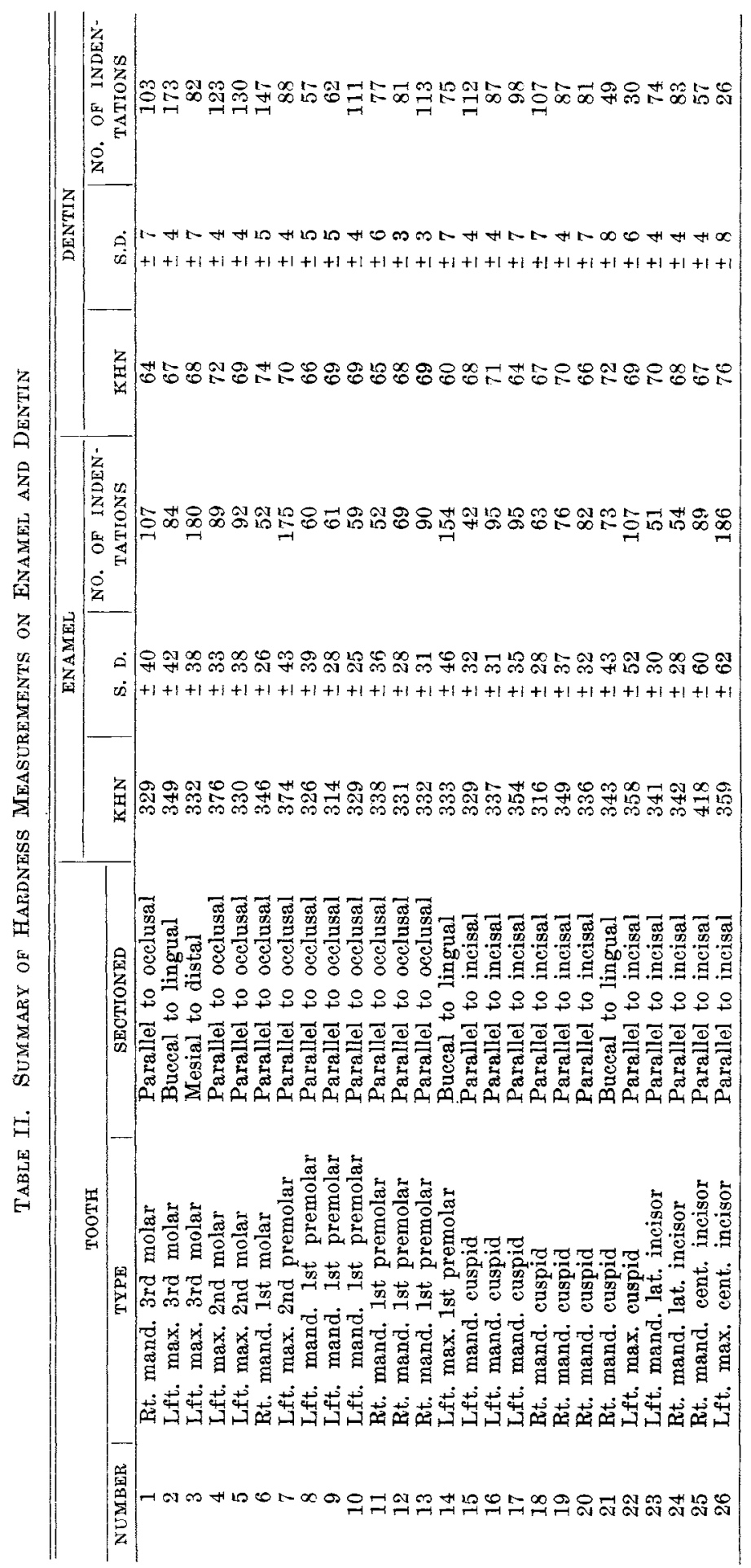


Since the indentations were placed at regular intervals and the number of indentations was large, this value of 15 per cent represents an approximate value for the macro areas of a tooth that are harder or softer than the average values reported.

\section{DISCUSSION}

The results presented for the hardness of enamel sections (KHN average 343) are in general agreement with those of Caldwell, Muntz, Gilmore, and Pigman ${ }^{10}$ on intact enamel surfaces (KHN average 380 ), which indicates that the inner enamel is of comparable hardness to surface enamel. The range of hardness values obtained in this research was 272 to 440 compared to 250 to 500 for the former investigation. It should be remembered that approximately 15 per cent of the measurements of this research were disearded for being outside the limits of experimental error or this range would be larger. The existence of these areas having large deviations in hardness from the average is substantiated by the work of Gustafson and Kling ${ }^{8}$ on the hardness of enamel and its relation to histologic structure.

A number of workers ${ }^{3,6,9,10}$ have reported that the enamel outer surface is harder than the inner enamel and that the hardness decreases from the outer edge to the dentinoenamel junction. Others ${ }^{8,13}$ have found no difference in hardness from the dentinoenamel junction to the outer surface. In the present study, the distance from the first indentation to the enamel surface was approximately $0.05 \mathrm{~mm}$. and, therefore, the first indentation does not actually represent the enamel surface. The data do show, however, that no significant differences in hardness existed from the dentinoenamel junction to the outer enamel edge. The most reasonable explanation for the various conclusions regarding the hardness trend in enamel has been proposed by Gustafson and

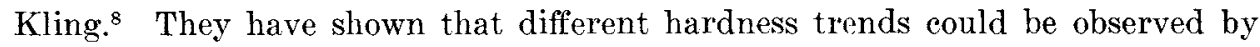
variation of the direction of a series of indentations in a single tooth section.

Hodge and McKay ${ }^{6}$ reported that dentin near the root was softer than near the erown of a tooth (Bierbaum Nos. 130 and 140, respectively). This trend was not observed in this study but would be difficult to establish since the per cent of variation reported above is about 7.5 per cent, which is of the same order of magnitude as the standard deviation reported in this paper.

\section{SUMMARY AND CONCLUSIONS}

The Knoop hardness numbers were determined for human enamel and dentin on sections of mature, freshly extracted, noncarious teeth. The over-all average hardness value for enamel and dentin for all teeth was $343 \pm 23$ and $68 \pm 3$, respectively.

Approximately 15 per cent of the hardness values obtained on both enamel and dentin had such large deviations from the average that they must be considered to be outside the range of experimental error and represent areas having exceptionally high or low hardness. 
No definite trend was detected in the hardness of enamel from the dentinoenamel junction to the outer surface or from the crown to the cervical margin. Likewise, no trend in hardness was observed in the dentin from one section of a tooth to another.

The greatest variation in the hardness in enamel was found just below the occlusal surface, although the average value for this type of section was not significantly different from the average values for other sections.

The assistance of C. R. Norris and G. G. Wepfer in determining the hardness values is gratefully acknowledged.

\section{REFERENCES}

1. Wright, H. N., and Fenske, E. L.: Factors Involved in Variability in Hardness of Tooth Struetures, J. D. Res. 17: 297, 1938.

2. Taketa, F., Perdue, H. S., O'Rourke, W. F., Sievert, H. W., and Phillips, P. H.: An Abrasion Method for Determining the Wear Resistance of Teeth. I. Description of Apparatus and Variables, J. D. Res. 36: 739, 1957.

3. Karlström, S.: Physical, Physiologieal and Pathologieal Studies of Dental Enamel With Special References to the Question of its Vitality, A. B. Fahlerantz Boktryckeri, Stockholm, 1931.

4. Proell, F. W., and Schubert: Die Ritzhärte des Schmelzes, Ztschr. Stomatol. 26: 1047, 1928.

5. Burg, F.: Neue spezielle Härtebestimmungen des Hartsubstanzen des Zahnes, Dissertation, Jena, 1921.

6. Hodge, H. C., and MeKay, H.: The Microhardness of Teeth, J.A.D.A. 20: 227, 1933.

7. Totah, V. P.: Increase in Hardness of Dentin on Drying, J. D. Res. 21: 99, 1942.

8. Gustafson, G., and Kling, $\ddot{0} .:$ Micro-hardness Measurements in the Human Dental Enamel, Odontol. Tidskr. 56: 23, 1948.

9. Atkinson, H. F., and Saunsbury, P.: An Investigation Into the Hardness of Human Enamel, Brit. D. J. 94: 249, 1953.

10. Caldwell, R. C., Muntz, M. L., Gilmore, R. W., and Pigman, W.: Microhardness Studies of Intact Surface Enamel, J. D. Res. 36: 732, 1957.

11. Hodge, H. C.: Hardness Tests on Teeth, J. D. Res. 15: 271, 1936.

12. Phillips, R. W., and Swartz, M. L.: Effect of Fluorides on Hardness of Tooth Enamel, J.A.D.A. 37: 1, 1948.

13. Klinger, A.: Studies on Enamel Hardness, D. Record 60: 291, 1940.

14. Knoop, F., Peters, C. G., and Emerson, W. B.: Sensitive Pyramidal Diamond Tool for Indentation Measurements, Nat'l. Bureau Standards, Journal of Research 23: 39, 1939.

15. Sweeney, W. T.: The Knoop Indentation Hardness Instrument as a Tool in Dental Research, J. D. Res. 21: 303, 1942.

16. Richardson, J. F., and Warner, H. K.: A Micro-Hardness Instrument for Studying Surface Hardness, Austral. J. Den. 49: 217, 1945. 